Editorial

\title{
Neonatal anesthesia and analgesia: time to reevaluate neurodevelopmental outcomes
}

Volume I Issue 6 - 2014

\section{Editorial}

Overall mortality and morbidity in infants and neonates undergoing a surgical procedure and general anesthesia in the USA is much higher than in older children. ${ }^{1}$ The reasons for this finding may be different neonatal/infant physiology, higher degree of illness, more complex surgical procedures and the effects of anesthesia and analgesia on developing brain. Importantly, the possible effects of blood pressure and cerebral perfusion changes during and after the surgery have to be elucidated in the future. ${ }^{2}$ A relatively large volume of animal data evaluating toxicity of anesthetic and analgesic agents on developing brain exists. Data from rodents and newborn monkeys have linked different agents to adverse neurodevelopmental outcomes, such as memory loss. ${ }^{3}$ and learning difficulties. ${ }^{4}$ The most commonly cited mechanisms of injury are increased apoptosis, impaired dendritic arborization and spine formation, changes in neurogenesis and neuronal cytoskeleton as well as altered mitochondrial function ${ }^{5}$

Extrapolation of animal data to humans is difficult due to different dosing and durations of anesthetic agents, less careful monitoring of the animals during the exposure (higher chance of developing hypotension, hypo/hypercarbia, hypoxia), lack of surgical stimulation (many animal experiments were performed without surgeries). In addition, plasticity of the human brain is higher with broader exposure to external stimuli (in contrast to the highly regulated laboratory environment). Lastly, our testing methods for neurodevelopmental evaluation in infants and children are more elaborate than those reserved for animals. While it is difficult to translate animal preclinical data to humans, an association between exposure to anesthetic agents and later learning deficits has been described.${ }^{6,7}$ A recent case series report ${ }^{8}$ describes development of infantile postoperative encephalopathy in six neonates who underwent general anesthesia, likely suffering from intraoperative cerebral hypoperfusion. This report reminds us not only the importance of perioperative blood pressure and end-tidal carbon dioxide monitoring but also displays the complexity of the surgery under general anesthesia.

In summary, there is an increased, renewed interest in outcomes related to neonatal surgery and anesthesia. This is exemplified by the Pediatric Anesthesia \& Neurodevelopment Assessment (PANDA) project, a large, ongoing, multi-center study assessing neurodevelopment and cognitive functions in children exposed to anesthesia. Funding opportunities exist from several agencies and societies, including International Anesthesia Research Society, to address this important pediatric patient safety issue.

\section{Acknowledgements}

None.

\section{Conflicts of Interest}

There is no conflict of interest.

\section{Thomas Havranek \\ Dept of Pediatrics/Neonatology,Albert Einstein University, USA}

Correspondence: Thomas Havranek, Associate Professor of Pediatrics, Dept of Pediatrics/Neonatology, Albert Einstein University, The Children $\square$ s Hospital of Montefiore, I825 Eastchester Road, Bronx, New York 1046I, USA, Tel 7I8-9044105, Fax 7I8-904-2659, Email thavrane@montefiore.org

Received: October 29, 2014 | Published: November 06, 2014

\section{Funding}

None.

\section{References}

1. Flick RP, Sprung J, Harrison TE, et al. Perioperative cardiac arrests in children between 1988 and 2005 at a tertiary referral center: a study of 92,881 patients. Anesthesiology. 2007;106(2):226-227.

2. McCann ME, Schouten AN. Beyond survival; influences of blood pressure, cerebral perfusion and anesthesia on neurodevelopment. Paediatr Anaesth. 2014;24(1):68-73.

3. Shih J, May LD, Gonzalez HE, Lee EW, et al. Delayed environmental enrichment reverses sevoflurane-induced memory impairment in rats. Anesthesiology. 2012;116(3): 586-602.

4. Paule MG, Li M, Allen RR, et al. Ketamine anesthesia during the first week of life can cause long-lasting cognitive deficits in rhesus monkeys. Neurotoxicol Teratol. 2011;33(2): 220-230.

5. Davidson A, Flick RP. Neurodevelopmental Implications of the Use of Sedation and Analgesia in Neonates. Clin Perinatol. 2013;40(3): 559573.

6. Ing $\mathrm{C}$, DiMaggio $\mathrm{C}$, Whitehouse $\mathrm{A}$, et al. Long term differences in language and cognitive function after childhood exposure to anesthesia. Pediatrics. 2012;130(3):e476-e485.

7. Flick RP, Katusic SK, Colligan RC, et al. Cognitive and behavioral outcomes after early exposure to anesthesia and surgery. Pediatrics. 2011;128(5):e1053-e1061.

8. McCann ME, Schouten AN, Dobija N, et al. Infantile Postoperative Encephalopathy: Perioperative Factors as a Cause for Concern. Pediatrics. 2014;133(3): e751-e757. 